\title{
MASIES
}

ECLA-BHG--8609

DE86 012973

UCLA-ENG-8609

PPG-935

\section{Elaatic Structural Analysis of the \\ Pin-Type Solid Breeder Blanket First Wall}

George E. Orlent and Nanr M. Ghonlew

February 1986

Thls work was supported by the U.S. Department of Energy, Orfice of Fusion Energy, Grant \#DE- 03-80ER52061, with UCLA. As

\section{DISCLAIMIRR}

This report was prepared as an socount of work sponsored by an ateacy of the United Stules Governmeat. Neither the Unitod States Government nor any apency thereof, nor any of their employees, makes any warranty, express or implied, of asumes any legel liability or respossibility for the accuracy, completeneas, or usefulnes of any informetion, apparatus, product, or process dieclosed, or represents that its use would not infringe privately owned rights. Refereace herets to any specific commercinl product, procens, os service by trade name, irodemart, manufecturer, or otherwise does not necesuarily constitute or imply its endorsement, rocommendation, or favoring by the United States Government of any agency thereof. The riems and opinions of authore expresed berein do not necessarily salte ar reflect those of the United States Gowernment or nny aseacy thereof. 


\section{DISGAII,}

This report was prepared as an account of work sponsored by an aseney of the linited scate Covernment. Nather the United states Covernent nor any agency thereof, nor anj of thatr enployees, wakes any wrranty. axpreas or 1mplied, or aesune ans legal 11ab111ty or reoponatbility for the sccuracy, copletenees, or usefulnese of any inforation, epperatus, product, or procene disclosed, or represente that its use would not infringe privetely owed rights. Reference heretn to any epectfic comerclal product, proceas, or sarvice by trade nam, tradeark, manufacturer, or otherwipe, does not necensarily constitute or 1aply its endorwerwent, recommation, or favoring by the Unted States coverment or any agency thereof. The view and opinions of authors expreseed herein do not necessarily state or reflect those of the Dnited States Governmet or any agency thereof. 


\section{Irmopoction}

A kay to the succensful dasign of a fusion blanket is the distribution of tha amount of structural meterial in the first wall and the blaniket oncloeing structure. The first wall mut support dynanic and static mechanical loads and at the sam tim sustain the therael gradients and orosion resulting from the plasen heat and particle fluxes. Dynanic and statie loade require high teaxural rigidity, which is influnnead by flow chamnala dasigned to cool the high heat flux incidant on the first wall. Since the first wall temperature is roughly proportional to its thickness, theraal tresses require a thin first wall. On the other hand, a thick wall Is necessary to withrtand aurface arosion due to particle fluxes. A feasible dosign must therefore repreaent an optimal solution satiafying such conflicting requirements.

The atructural dasign of the breeder blankot must not only satisfy the steady state operating condition, but must also met cyclic condition: due to start-ups, shut-down and non-steady operation. Fatigue of the first wall, crack propagation under cyclic load and realdual stress build-up are sons of the wot important issuer related to ropetitive loading conditions. Another problem arising from the time history of the loads is thermal shock due to power ramps. One also has to consider energency situations such as loss of pressure.

Throughout Its life, the blanket will be subjected to a radiation environment causing radiation induced creep, swelling, and embrittlement. Although creep has a tendency to relieve high stresses due to thermal gradients, It can cause large displacenents. Under axially restrained conditions creep buckling and high stresses due to swelifng may be important. Loss of the structural material due to erosior must also be considered so that the module can sustain the loads under end of life conditions. A satisfactory structural design requires that all of these operating conditions be at without loss of structural integrity of the systen.

To address some of the Issues described above and gain some insight into scaling, a displacenont type finite elenent nodel, based on classical beam theory, has been developed.

\section{YODERLING}

The first wall structure is nodeled here as an assembly of curved I beans. Then the resulting thermolasticity problem is solved using a displacenent type finite elenent formulation. The curved bean is discretized In 2D-frame elements. The following assumptions have been adopted:

1. A honogeneous, Isotropic, Innearly elastic naterial,

2. Linear thernal expansion,

3. Cross sectional dinensions are snall compared to the radius of curvature. 


\subsection{Stiffinese kntrix and Congistent Loud Vectors for a 2-D Frese Eilenent}

When deriving a displacenent type finite elenent formulation, one has to choose a displacenent field wich satisfies the following conditions:

- it can describe the rigid body wotions of a particular element,

- it has sufficient freedor to allow kinesatic continuity between the elesonts,

- it can produce a displacoment pattern corresponding to the constant strain state of the lowents. This requirement is necessary for the - lewent in order to be able to converge to the true strain state upon refining the partition of a body in a general strain state.

Conafder a two-dinonelonal frawe element given in Fig. I. Its behavior for small displacenents is a superposition of that of a bar and a bean. Lot $u(x)$ and $v(x)$ denote the axial and traneverse displacesents in the local coordinate systen. Leter quantitias will be expressed in a global coordinate systen. The global quentities will be denoted by a prine. The nodal displecenent quantities associated with a frame elesent are the axial and transverse componants of the motion, $u, v$ and the rotation at the nodal points, $\beta$. The corresponding force and wonnt quantities are $F_{x}, F_{y}$ and $M$. Subscripte 1 and 2 refer to the arbitrarily chosen "beginning" and the "end" of the element. Traneverse and axial distributed line loads are denoted by $p$ and $q$, respectively.

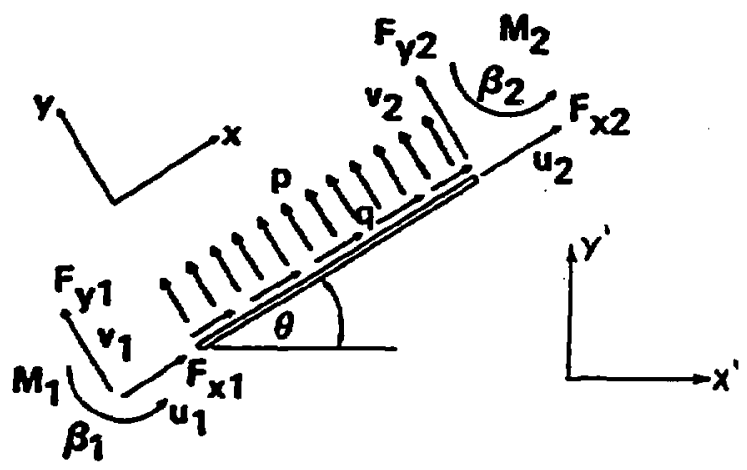

Fig. 1. Forces and displacements on a 2-D frame element

Consider a linear interpolation for $u(x)$ and a cubic interpolation for $v(x)$. The rigid body motion of a bar is a translation which is clearly included in - IInear displacement field. Since the nodel degrees of freedon are $u_{1}$ and $u_{2}$ in the exial direction, Inter-element continuity is gunranteed. For a bar, the extensional strain is equal to the first dorivative of the axial displacenent field; consequently, a linear interpolation function permits a constant strain state. The rigid body notions of a bean are uniforn transverse translation and a rotation which are included in a cubic field. 
There are four geniralfzed nodal degrees of froedon, becaure claseical ben theory requires that the diaplacement and the slope to be contimous between elesents. This mikes It necessary to choose at least a cublc interpolation function. The constant strain wode for thin basin is a constant curiature, which requires a diaplecement at leat quadratic in the axial coordinnte.

Thus,

$$
\begin{aligned}
& u(x)=k_{-}^{T} u_{2}-[1-\xi]\left[\begin{array}{l}
u_{1} \\
u_{2}
\end{array}\right] \\
& v(x)=H^{T} t H_{2}=\left[\begin{array}{llll}
1-3 \xi^{2}+2 \xi^{3} & d\left(\xi-2 \xi^{2}+\xi^{3}\right. & 3 \xi^{2}-2 \xi^{3} & d\left(-\xi^{2}+\xi^{3}\right)
\end{array}\right]\left[\begin{array}{l}
v_{1} \\
\beta_{1} \\
v_{2} \\
\beta_{2}
\end{array}\right]
\end{aligned}
$$

where $\xi$ denotes $x / d$ and $d$ is the length of the lement. The axial strain is expressed in terns of the displacement field as follows (Euler-Bernoulli beam theory):

$$
\epsilon x=\frac{d u}{d x}-y \frac{d^{2} y}{d x^{2}}
$$

The axial stress is given by linear stress-strain relatlons:

$$
\sigma_{x}=E\left(\epsilon_{x-a T}\right)
$$

And the strain energy is:

$$
U-\frac{1}{2}\left(\epsilon_{x}-a T\right) \sigma_{x}-\frac{E}{2}\left(\epsilon_{x}-a T\right)^{2}
$$

The total potential energy of the elemont $1 \mathrm{~s}$ defined as:

$$
\mathbf{v}=\mathbf{U}+\mathbf{v}_{\mathbf{g}}
$$

where the potential energy of the external forces is given by:

$$
\begin{gathered}
v_{E}=-F_{x 1} u_{1}-F_{x 2} u_{2}-\int_{0}^{d} p(x) u(x) d x-F_{y 1} v_{1}-F_{y 2} v_{2} \\
-H_{1} \beta_{1}-H_{2} \beta_{2}-\int_{0}^{d} q(x) v(x) d x
\end{gathered}
$$

Applying the theoren of minimun potential energy, $\delta V-0$ leads to the complete stiffness relation: 


$$
\left[\begin{array}{l}
x_{1} \\
y_{1} \\
u_{1} \\
x_{1} \\
y_{2} \\
u_{2}
\end{array}\right]=\underline{K}\left[\begin{array}{l}
u_{1} \\
v_{1} \\
\beta_{1} \\
u_{2} \\
v_{2} \\
\beta_{2}
\end{array}\right]-\underline{P}-\underline{B}_{T}
$$

$$
\begin{aligned}
& \begin{array}{l}
K=E / d[A \\
R=\left[\begin{array}{c}
\mathrm{pd} / 2 \\
\mathrm{qd} / 2 \\
\mathrm{qd} / 12 \\
-\mathrm{pd} / 2 \\
\mathrm{qd} / 2 \\
-\mathrm{pd}^{2} / 12
\end{array}\right]
\end{array} \\
& F_{T}-\int_{A} \operatorname{\alpha T}(y, z) d A \\
& R_{T}=\left[\begin{array}{c}
-F_{T} \\
0 \\
S_{T} \\
-F_{T} \\
0 \\
-H_{T}
\end{array}\right] \\
& M_{T}-\int_{A} \operatorname{yot}(y, z) d A
\end{aligned}
$$

where A denotes the area of the cross section and I is the moment of inertia. The tranaverse and axial loads are taken constant over the lerigth of an element to obtain the consistent load vector in (10). The terperature field $T(x, y, z)$ has been replaced by

$$
T(y, z)-\frac{1}{d} \int_{0}^{d} T(x, y, z) d x
$$

which does not affect convergence if one takes fine enough partitions to capture the change of the thereal field in the $x$ direction. It can be observed that thermal effects appear as a consistent load vector. It can also be shown that the stiffness matrix, $K$ exhiblts all the necessary rigid body notions and constant strain modes is it can be anticipated fron the orders of interpolations used to describe the displacenent field.

For practical applications, it is convenient to express the nodal displacements and forces in terns of globsl coordinates. The transfornation is given by the following relations:

$$
\left[\begin{array}{l}
u^{\prime} \\
v^{\prime} \\
\beta^{\prime}
\end{array}\right]=\left[\begin{array}{cll}
\cos \theta & \sin \theta & 0 \\
-\sin \theta & \cos \theta & 0 \\
0 & 0 & 1
\end{array}\right]\left[\begin{array}{l}
u \\
v \\
\beta
\end{array}\right]-\underline{T}_{1}\left[\begin{array}{l}
u \\
v \\
\beta
\end{array}\right]
$$




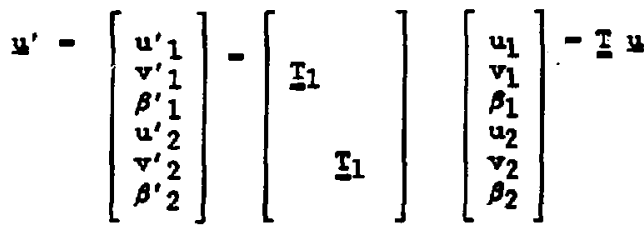

$$
\begin{aligned}
& \mathbf{P}^{\prime}=\underline{\mathbf{T}} \mathbf{R} \\
& \mathbf{P}^{\prime} \mathbf{T}=\underline{\mathbf{T}} \mathbf{R}_{\mathrm{T}} \\
& \underline{K}^{\prime}-\mathrm{K}^{\mathrm{T}} \mathbf{K} \mathrm{I}
\end{aligned}
$$

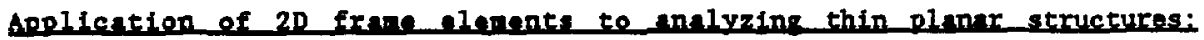
bounding aonditions.

In ordar to apply the prevlowe sethod to the analyals of the first wall, we first define a discretization sethod of 1ta structure. Then, it is assuned that the elesents are Intorcomected at nodal points, and therefore, syaten stiffnase rolation is established. This takes a form simflar to that of an element stiffnase relation,

$$
\mathrm{K} \boldsymbol{n}=\mathbf{E}
$$

where $\mathrm{K}$ is a banded antrix. The bandwidth is daternined by the numbering of the nodes.

Next, we nedify the stiffness relation by lncluding boundary conditions. For example, built-in conditions are achieved by setting both displacenents and slope to zero at the boundery, $1 . \bullet$. ,

$$
u=0, v=0, \beta=0
$$

while symetry with raspect to a horizontal axis is modeled by setting the axial displacenent and the slope zero,

$$
v=0, \beta=0
$$
allowed:

Finally, a simple support condition is such that only rotation is

$$
u=0, v=0
$$

To delete the $1^{\text {th }}$ degree of freedon, we simply zero out the $1^{\text {th }}$ row and $i^{\text {th }}$ colum of the system and replace $k_{i 1}$ by one. This guarantees that upon solving the equation, the $i^{\text {th }}$ displecement corponent will be zero. Using elament stiffness relation, we then solve for nodel forces and hence nodal stresses.

The modeling process described above is applled as follows: Taking advantage of symetry one half of the first wall in one blanket module is considered. This is realistic, since the blanket structure and the loads are 
symetric. The corresponding boundary conditions are (16) at the location where the nefghboring wodules met and (17) at the middle of the segment. To discretize the structure, we divided it into five segants. Calculations to check accuracy using ten segants are also performed. It is found that approximately five eegants give an accurate representation of the stress distribution. Integrals appoaring in the expressions for thernal forces and mowents are calculeted by simpon's rule uaing 12 partitione of the eross sections.

\section{RESULTS OF GAICUIATIOHS}

F1g. 2 shows the pure pressure stresses at beginning of life. It can be obsecved that the stresses are posicfive due to the internel pressure and the support gives rise to local bending. As a result, the stresses at the plasma aide tond to be less positive, while the Inner side stresses ara increased. The design 11nit for the primary stresses at the operating temperature is approxtautely $170 \mathrm{MPa}$. To allow for acrificial layer for eroaton, the plesen side of the first wall is thickened.

Results for thermal and pressure stresses for this design, based upon a teaperature profile without a central fin a discussed in reference $[1]$, are given on Fig. 3.-6. Based on the assumption that the support behind the manifold allows thermal expansion of the whole unit, the bare temperature for the thermal strain is taken as the Inlet coolant temperature. The plasma side of the first vall experiences compression due to the higher temperatures. The relatively high level of the stresses results from the interaction between the high bulk temperature and the supports, as well as the gradients across the first wall. It is found that bulk temperature is the more important factor here, since azfmuthal variation of the stresses was not large.

In order to rechuce the bulk temperature, fins in the coolant channels and surface roughening have been amployed to improve heat transfer between the coolant and the structure. Fig. 3. and 4. show total stiesses with one fin in the coolant channel and with and without surface roughening. Improvenents due to surface roughening are relatively because only a small fraction of the total surface is asenined to be roughened. On Fig. 5. and 6. the effect of surface roughening can be observed when there are two fins present in the coolant channol. The stresses are lower than the values for the single fin configuration, primarily because of the lower bulk tenperature. The values are relativaly high, but referring to the design guidelines for secondary stresses published in reference [3] they are allowable. At operating tenperature the allowable prinary stress for C-9 is about $170 \mathrm{MPa}$. The design linft for secondary stresses which include thermal stresses is thrae times the value for the primary stresses.

Fig. 7 illustrates what the pressure stresses night look like at the end of life assuning three full-power years of operation and 1 m/year erosion rate. The point here is that the pressure scresses are below the allowable linit. Stresses shown here are to be taken only as estinates, since many processes neglected here may aignificantly alter the elastic state of the structure. 


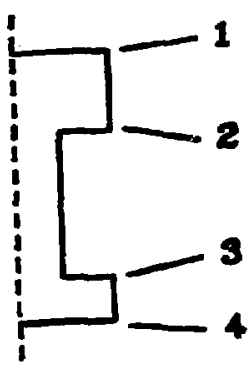

PRESSURE STRESSES IN THE FIRST WALL BEGINNING OF LلIFT

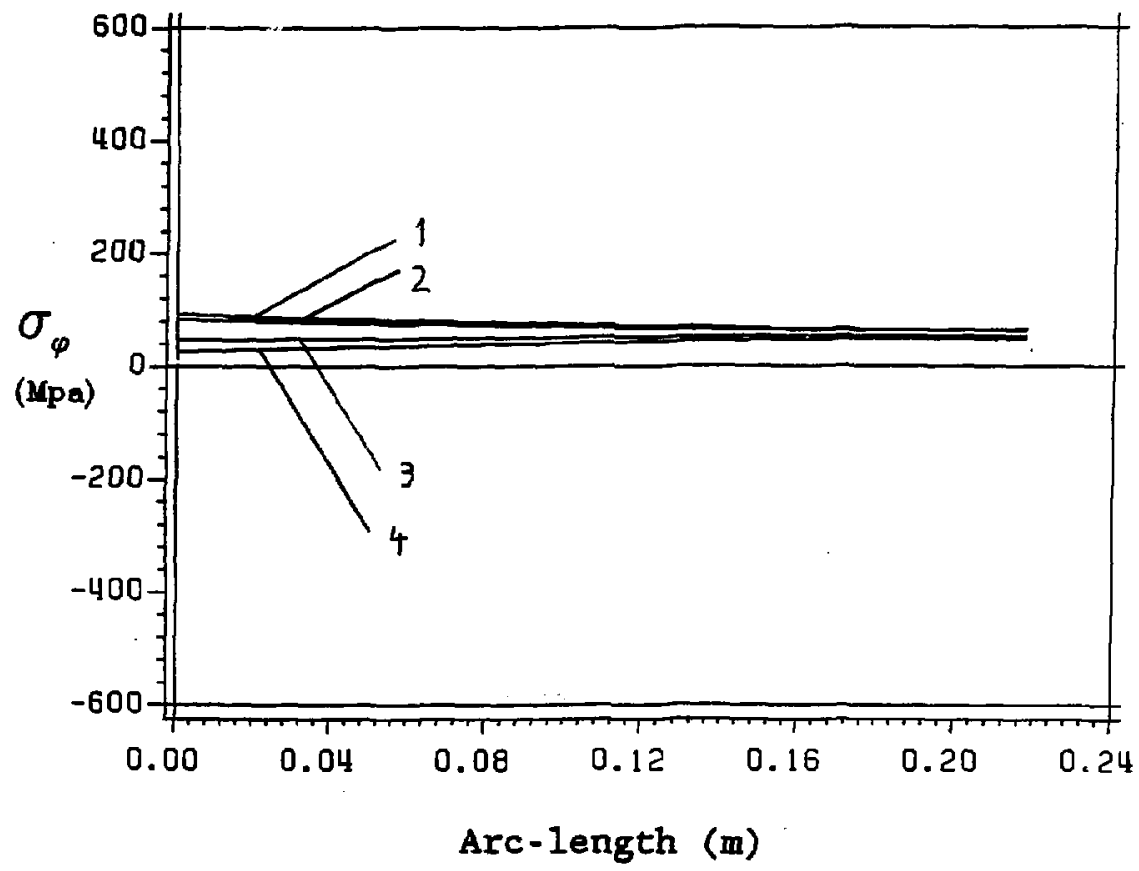

Fig. 2. 
PRESSURE AND THERMAL STRESSES IN THE FIRST WALL BEGINNING OF LIFE ONE FIN, NO ROUGHNESS

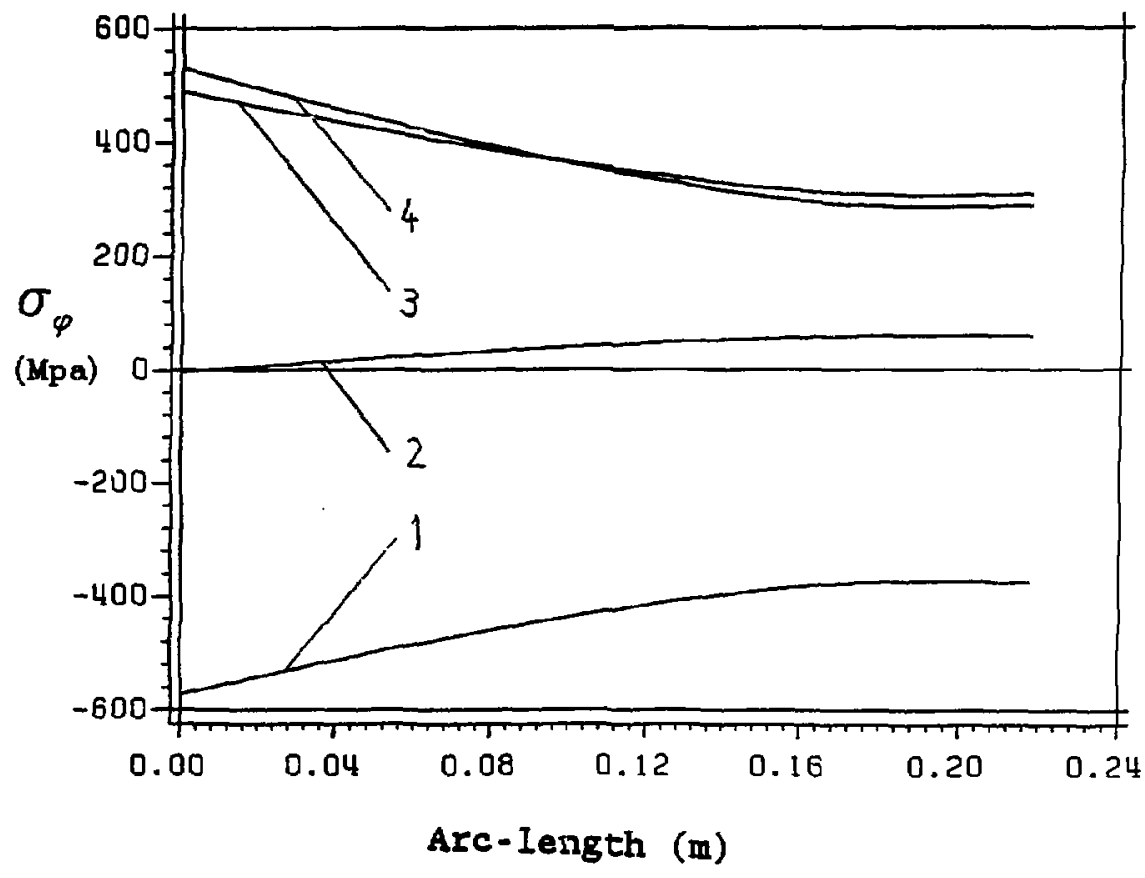

Fig. 3 . 
PRESSURE AND THERMAL STRESSES IN THE FIRST WALL BEGINNING OF LIFE

ONE FIN WTTH ROUGHNESS

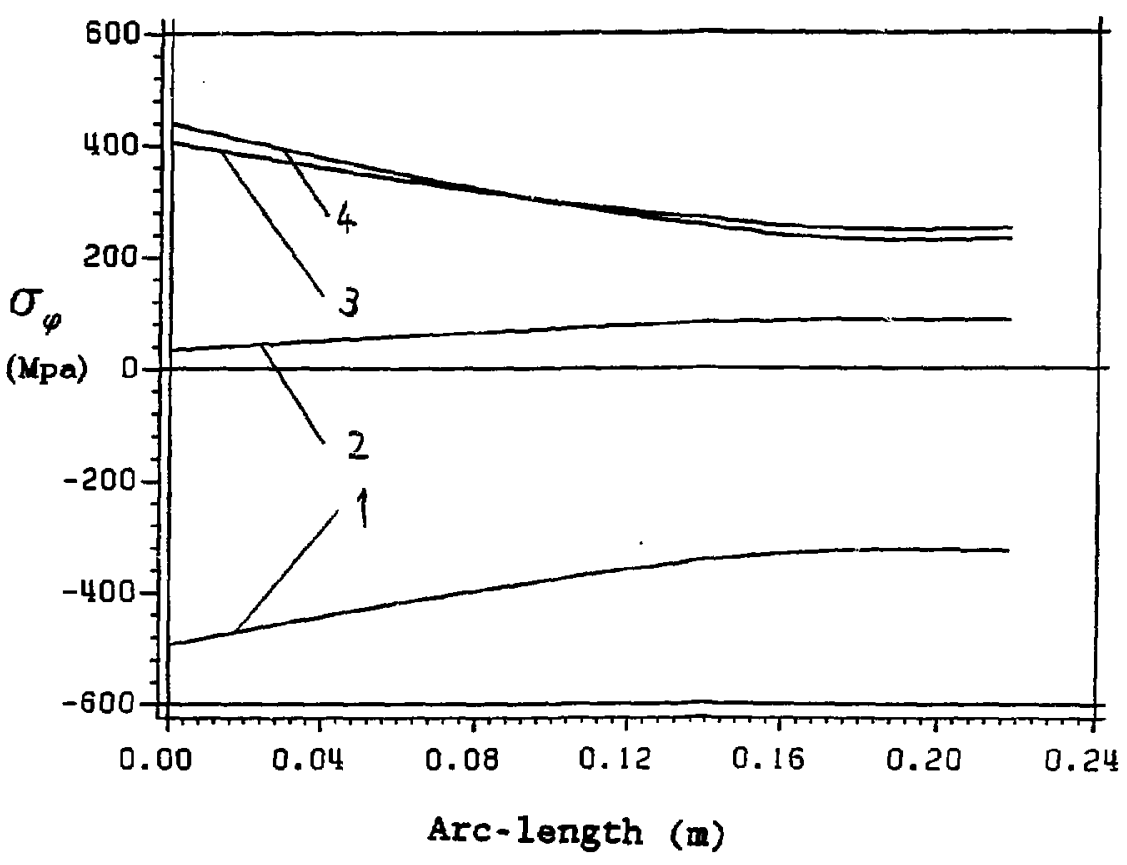

Fig. 4. 
PRESSURE AND THERMAL STRESSES IN THE $\neg$ IRST TALL BEGINNING OF LIFE

TIO FINS, NO ROUGFNESS

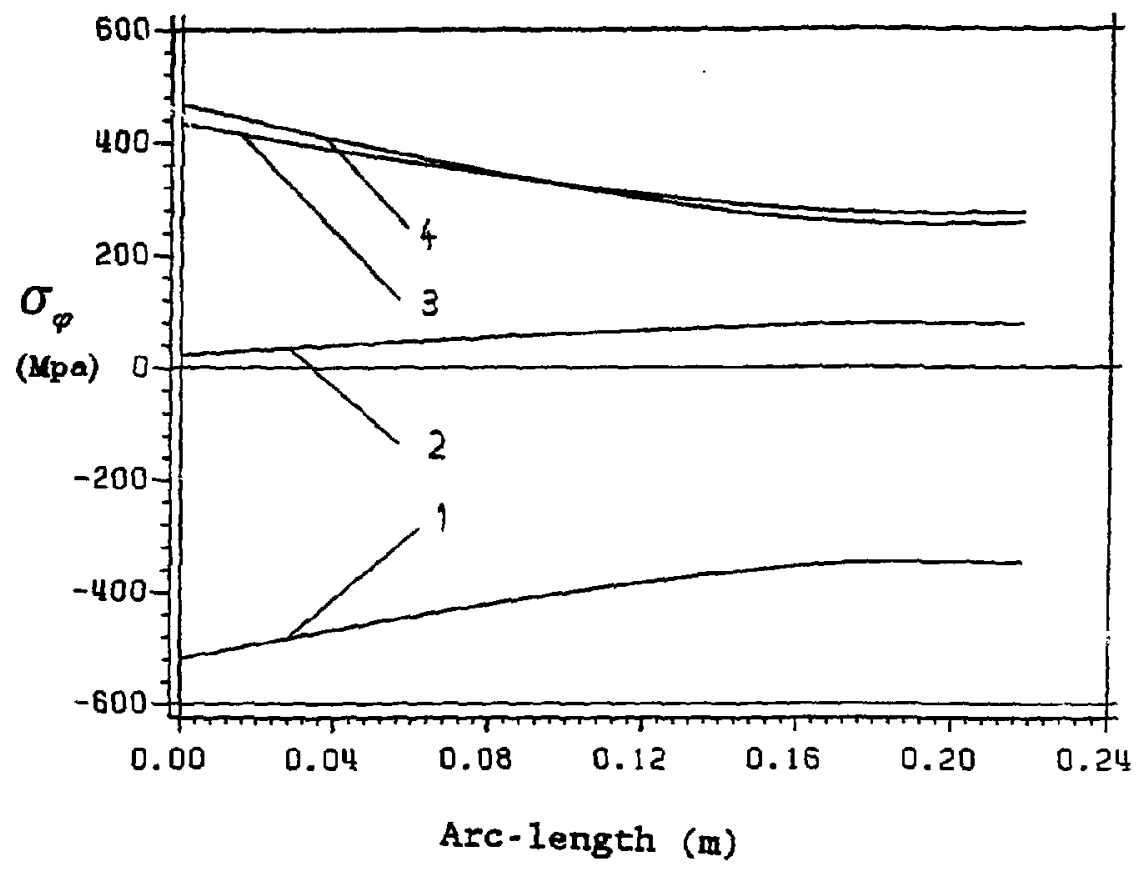

Fig. 5 . 
PRESSURE AND THERMAL STRLSSES IN THE FIRST WALL

BEGINNING OF LWFE

TWO FINS FITH ROUGHNESS

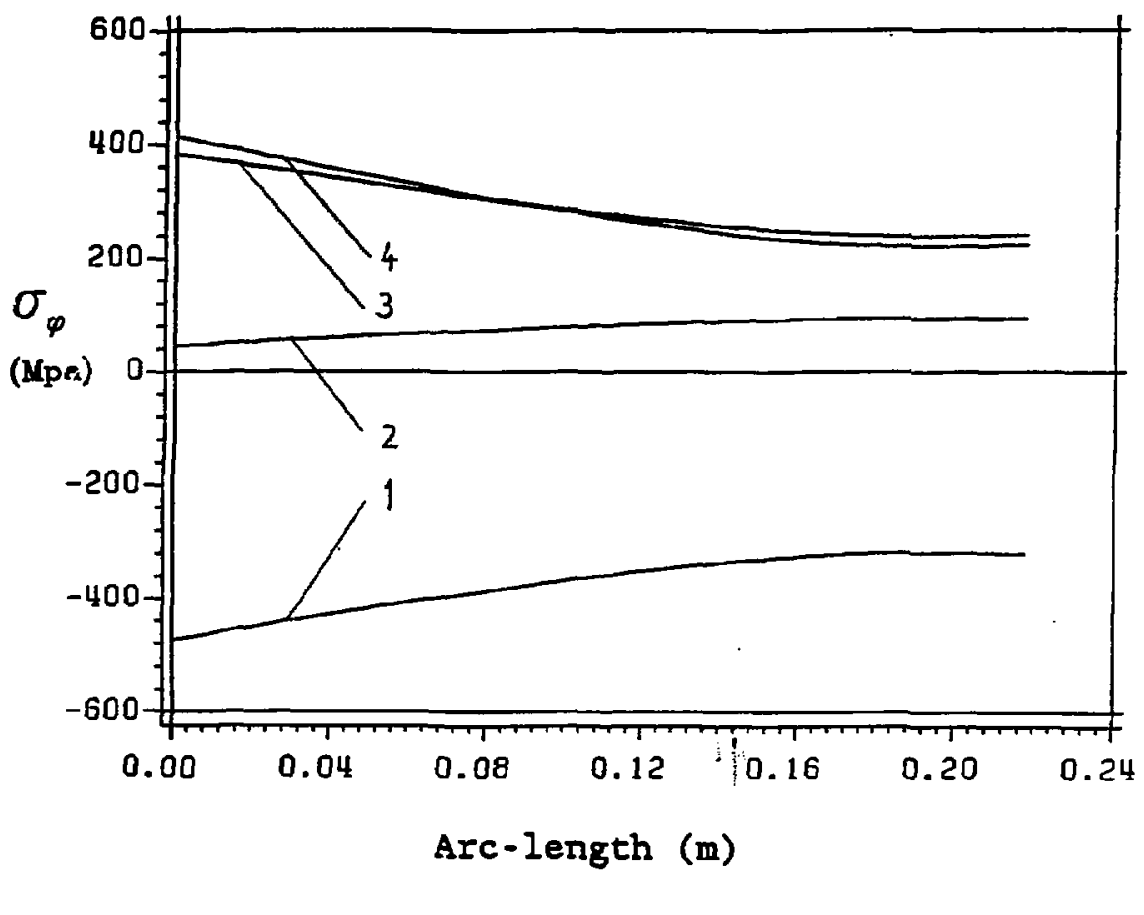

Fig. 6. 
PRESSURE STRESSES IN THE FIRST WALL END OF LIFE

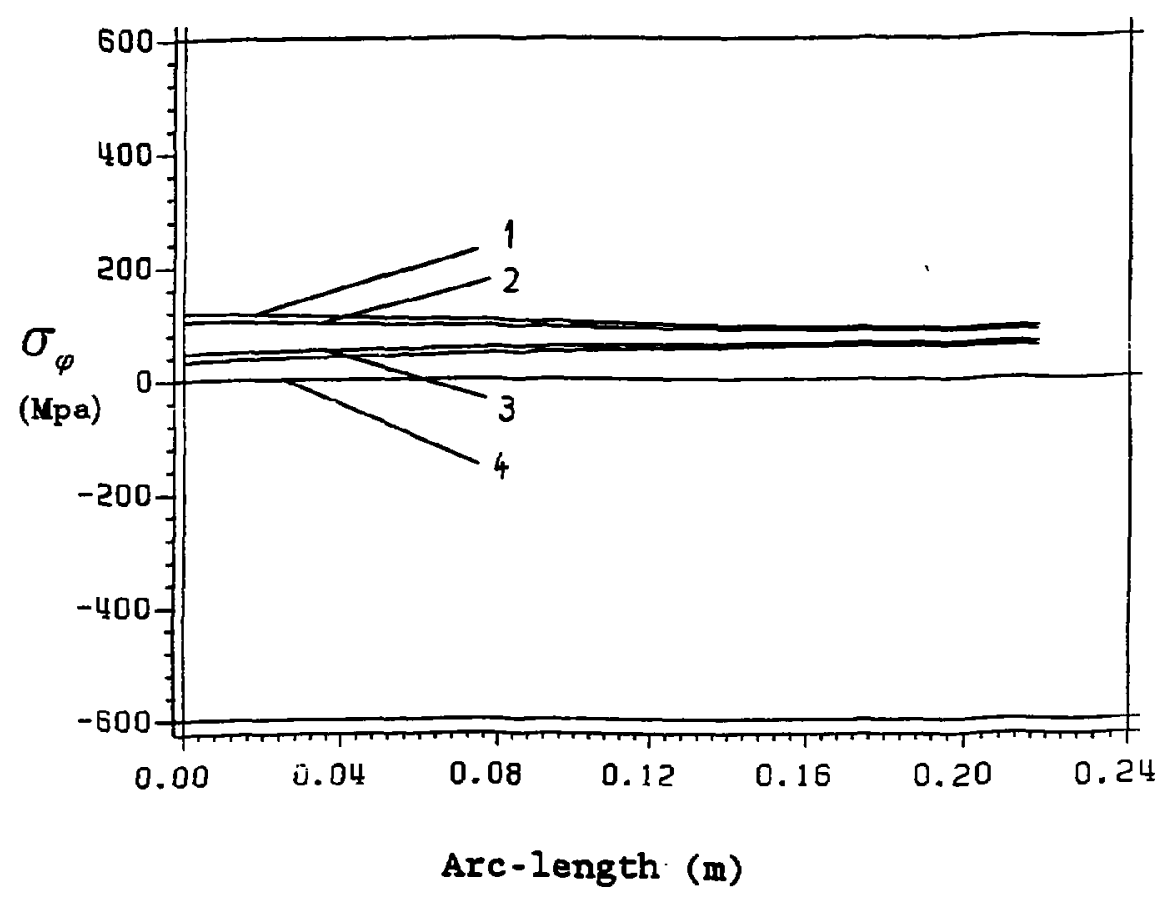

Fig. 7 . 


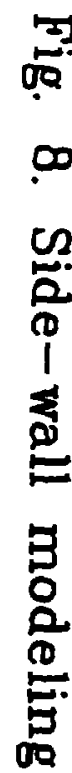

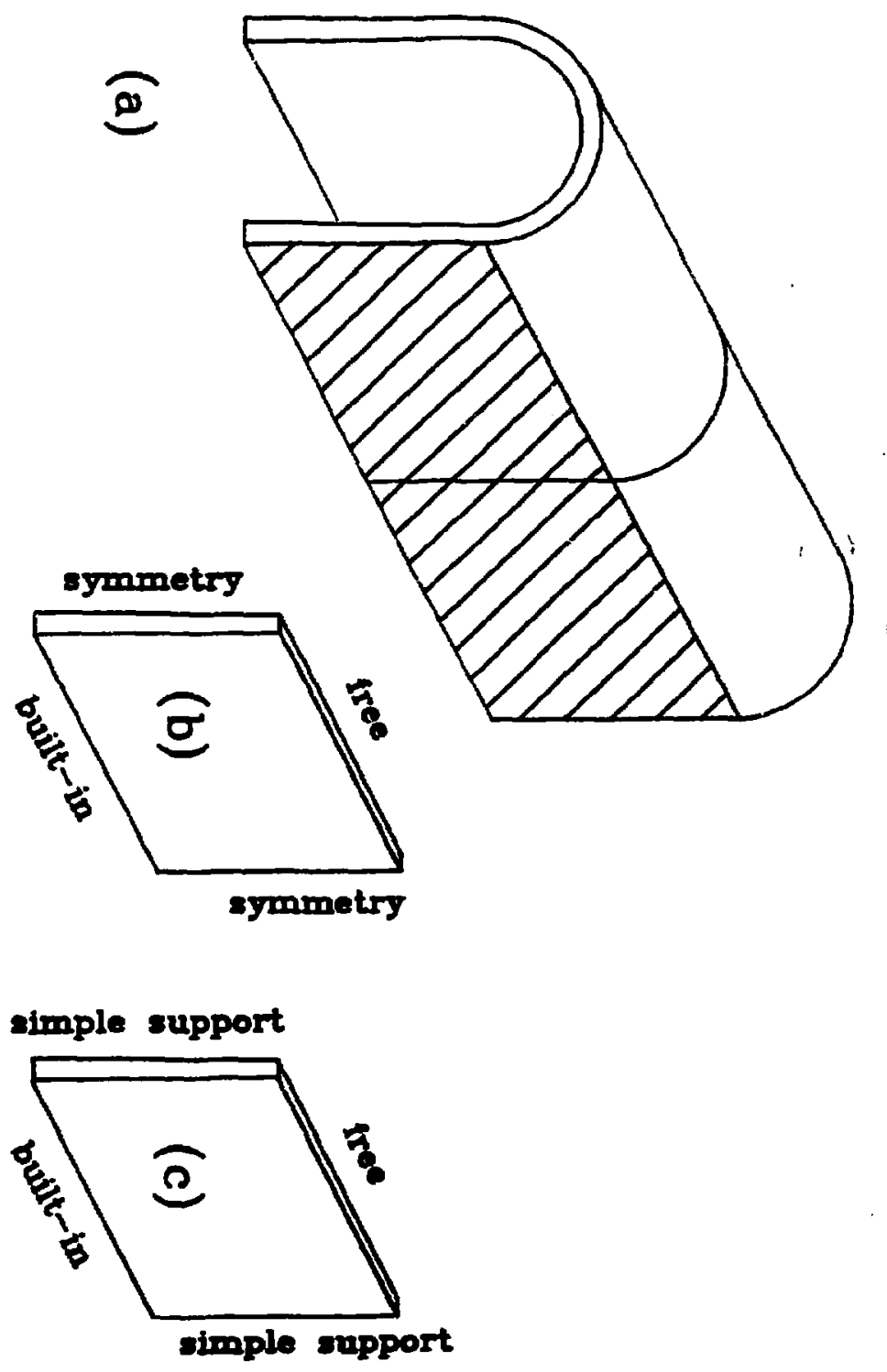




\section{ANALYSIS OF THE STDE-WALI.}

In order to attain Inherent structural safety, the desfgn of the blanket must be faflure tolerant. Losa of pressure or rupture of a nodule must not start a catastrophic chain of failures propagating through the whole blanket. As the worst case one can consider a single module loaded by the Internal pressure of the coolent, while the notghboring wodule suffered total loss of pressure. In order to be safe, a module has to be able to support the pressure without the equalizing preseure on the side walls resulting from the presence of the adjacent pressurized nodule. In principle, a tapered side wall could reault in an optinel load carrying atructure and mininal inpact on the blanket performance, since the addad structural material would appear at the back of the blanket. However, the loads and the geonetry of our design would require excesalvely thick side wall at the inlet manifold. Altermetively, periodic supports as shown on Fig. 8 along the axis of the module can add the necensary etiffness to the side wall. The necessary spacing can be estinated as follows:

Consider the rectangular segment of the side wall bounded by the manifold, the supports and the cylindrical part of the first wall. Relaxing the connectivity conditions at the top of the segnent, the boundary conditions are those shown in Fig. 8. (b). Further relaxing the symetry conditions at the vertical edges of the segment, simple supported conditions can be used. This nodeling process is rather conservative, but will yield a safe geonstry. As it turns out, it is necessary to assume a mechanical coupling between the side walls of the adjacent modules in order to achieve a flexural rigidity thet permits reasonble spacing between the supports.

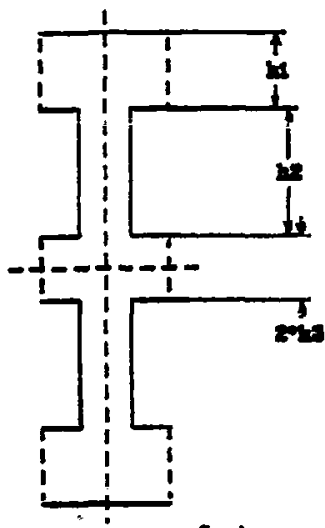

Fig. 9. Cross section geositry of the coupled side-wall

The flexural rigidity of a double-chanelled cross section as shown on Fig. 9. is given by 


$$
D=\frac{T}{1-\nu^{2}} \int_{A} y^{2} d y=\frac{x}{1-\nu^{2}}\left(\left(h_{1}+h_{2}+h_{3}\right)^{3}-\left(h_{2}+h_{3}\right)^{3}+h_{3}{ }^{3}\right)
$$

after neglecting the walls of the channols.

The axximum stress occure in the middle of the free edge and at the outer fiber it is given by [2]

$$
\sigma-\frac{E\left(h_{1}+h_{2}+h_{3}\right)}{2\left(1-\nu^{2}\right)} \frac{b^{2}}{D(b / a)^{2}} p
$$

where $p$ is the coolant pressure, a is the distance between supports, b/a is the aspect retio of the rectangular plate and $\beta$ is a numerical factor tabulated for different aspect ratios on page 210 of reference [2]. For the current dasign $h_{1}=0.025 n h_{2}=0.01 n$ and $h_{3}=0.005 n$ and $b=0.6 n$ resulting $0=7.84$ MPa $\mathrm{a}^{2}$. An apect ratio b/a-1/3 ylelds $251 \mathrm{MPa}$ maximum tress. Noting that it occurs at the niddle of the free end in the nodel, which is a connection line to the cylindrical surface in the real structure this value is acceptable. Safer still, if $\mathrm{b} / \mathrm{a}-1 / 2$ then the maximm strose is $110 \mathrm{MPa}$, therefore supports at every 1.2 a vill provide enough rigidity.

\section{DISCUSSION OF LTMYTTATTONS AND UTGERTATINTIDS}

Wh1le this model 1s based upon a finite elenent model to the first wall geonetry, it has not eccounted for several important enpects. Future efforts may be necessary to resolve the importance of these aspects, which are discussed below:

1. Further elestic-plastic analysis is necessary to better understand the scaling of gaowetry, since the strasses exceed the elastic limit. Furthermore, residual stress bulld-up due to gyslis lised should also be calculated.

2. The built-in and condition at the jointe with the side walls is valid, since there is no rotation and tranelation in the radial direction due to symmetry. Transiation in the tangential direction is negligible compared to displacenents in other locations, because temperatures are the lowest at the joint. Application of symatry conditions in a continuous curved bean at the top of the arch may not be realistic, depending upon the real geometry at this point. If a channel is present there, a hinge type boundery condition may be a better approxination, if a significent portion of the cross section is removed. In this case, a detailed analyols is necessary to quantify stress concentrations around coolant channels.

3. Swelling is significant phenonenon for an axially restrained structure, such as a curved nember. The equivalent thermal field arlaing from swelling is superposed on the real tomperatures and can cause high strenses.

4. Since the structure is ande of a ferritic alloy (9-C), significant body 
forces may be present due to the mennetic field, and proper analysis should address this question. If the distribution of the wignetic body force field is known then the tangential and normal components can be calculated and input as distributed transverse and axial loads in equation (10).

5. Since the terperatures throughout the first wall structure are high, both thermal and irradiation creep are expected to play eignificant role during the Iffetine of the blanket. A treatent of the creep contribution is discussed in reference [4] and is directly applicable to this problen.

6. Swelling atrains could be easily incorporated sinilarly to the consistent loads due to thermal straine given in equation (10).

7. Time dependent erosion can be included when total tine analysis is performed by changing the cross section geosetry as the solution continues.

ACKNOKLEDGEXGATI

This work was supported by the U. S. Department of Energy, Office of Fusion Energy, Grant \#DE-FG03-80ER52061, with UCLA.

\section{References:}

[1] Grotz, S. and Ghoniem, N. M. (1986) Thernal Analysis of a Pin Type Blanket for Tokanak Reactors.

[2] Timoshenko, S., Wolnowsky-Krleger, S. (1959) Theory of Plates and Shells, McGraw-Hill

[3] Iupurity Control and $1^{\text {sE }}$ wall engineering, Chapter VII. FED - INTOK/ICEW/82-17

[4] Orient, G. E.,Glerszewekf, P.,Garner, J. G. "Elastic-Plastic Analysis of Slender First Wall Structures", Busion Technology Vol. 8., 1985 July pp. 586-591. 